\title{
Effect of Processing Parameters and Ascorbic Acid on the Electrodeposition NiFeW Alloy Coatings
}

\author{
Yu Jinku ${ }^{1}, \quad$ Zhao Lili $^{1}, \quad$ Sun Hui ${ }^{1}, \quad$ Wang Yuehua ${ }^{1}, \quad$ Yu Meiqi $^{2}, \quad$ Luo Hongliang $^{2}, \quad \mathrm{Xu}$ \\ Zhefeng $^{2}$, Kazuhiro Matsugi ${ }^{2}$ \\ ${ }^{1}$ State Key Laboratory of Metastable Materials Science and Technology, Yanshan University, Qinhuangdao 066004, China; ${ }^{2}$ Graduate \\ School of Engineering, Hiroshima University, 1-4-1. Kagamiyama, Higashi-Hiroshima, Japan 739-8527
}

\begin{abstract}
In order to obtain $\mathrm{NiFeW}$ alloy coating with good performance, we studied the influence of $\mathrm{pH}$ value, temperature, current density, and the concentration of ascorbic acid stabilizer on the composition, deposition rate, and microhardness of NiFeW alloy coating. The results show that the $\mathrm{pH}$ value of plating bath largely influences the concentration of $\mathrm{W}$ and the deposition rate of the coating; the temperature of plating bath greatly affects the deposition rate, composition, and microhardness of the coating; upon increasing the concentration of ascorbic acid, the deposition rate of the coating decreases whereas the surface morphology of coating becomes more rough. With the $\mathrm{pH}$ value of plating bath equal to 4 , temperature of $60{ }^{\circ} \mathrm{C}$, current density of $4 \mathrm{~A} / \mathrm{dm}^{2}$, and ascorbic-acid concentration of $3 \mathrm{~g} / \mathrm{L}$, the deposition rate and the hardness of the coating are high. In addition, both the surface quality and the corrosion resistance of the coating are good.
\end{abstract}

Key words: NiFeW alloy coating; electrodeposition; microhardness; corrosion resistance

Tungsten alloy coatings have attracted interests from many researches in recent years due to their high melting point, high hardness, high wear resistance, and good anti-friction performance. It has been found that adding element $\mathrm{W}$ into $\mathrm{NiFe}$ alloy can refine grains, improve the uniformity, and increase the surface hardness and the high-temperature performance of the alloy coating ${ }^{[1-3]}$. NiW alloy coating has a dense structure and high hardness. It is not only highly heat resistant and wear- and oxidationresistant at high temperature, but also self-lubricating and corrosion resistant ${ }^{[4-6]}$. Nanocrystalline NiFeW alloys, which combine the advantages of NiW alloy and FeW alloys, have high hardness and good wear and corrosion resistance ${ }^{[7-11]}$. The influence of $\mathrm{W}$ content on the microstructure and property of coatings, as well as the formation of $\mathrm{NiFeW}$ alloy coatings, which are formed by electrodeposition in the citric acid/ammonium salt system and studied by cyclic voltammetry, have been previously studied ${ }^{[12,13]}$. The effect of main salt concentration and temperature on the $\mathrm{NiFeW}$ alloy coating was studied, and the optimum technological conditions were selected by the analysis of the hardness, deposition rate and appearance ${ }^{[14]}$. However, the influence of deposition parameters on the deposition rate of coating has not been studied. There is not detailed study on the influence of ascorbic acid on the property of the coating.

In the present work, we prepared $\mathrm{NiFeW}$ alloy coatings by electrodeposition and measured their chemical composition. We studied the influence of electrodeposition conditions on the deposition rate and the composition, hardness, and corrosion resistance of the alloy coatings. In particular, we studied the influence of ascorbic acid stabilizer on alloy coatings and analyzed the relationship between the deposition rate and the concentration of ascorbic acid. By comparing the corrosion resistance of the coatings prepared at four different conditions, we achieved

$\overline{\text { Received date: February 14 }}, 2017$

Foundation item: the Colleges and Universities of Science and Technology Research Projects of Hebei Province in China (ZD2014055)

Corresponding author: Yu Jinku, Ph. D., Professor, State Key Laboratory of Metastable Materials Science and Technology, Yanshan University, Qinhuangdao 066004, P. R. China, Tel: 0086-335-8074792, E-mail: yujinku@ysu.edu.cn 
the optimum deposition parameters for the NiFeW alloy coatings prepared by electrodeposition.

\section{Experiment}

To improve the surface quality of plating substrate, we used a commercially available copper plate with a dimension of $20 \mathrm{~mm} \times 20 \mathrm{~mm}$ as the substrate and performed the following pretreatments before plating: the substrate was first immersed in a $10 \%$ sulfuric acid solution to remove the copper oxide on the surface; and then immersed in a $20 \mathrm{~g} / \mathrm{L} \mathrm{Na}_{2} \mathrm{CO}_{3}$ solution and $2 \mathrm{~mL} / \mathrm{L} \mathrm{OP}-10$ emulsion solution, to remove cutting oils; washed by $60^{\circ} \mathrm{C}$ hot water and cold water, respectively; weakly etched in a $5 \% \mathrm{H}_{2} \mathrm{SO}_{4}$ solution for $30 \mathrm{~s}$; and finally washed with deionized water.

The following chemicals, 3.6 6.8 g/L FeCl${ }_{2} \cdot 4 \mathrm{H}_{2} \mathrm{O}, 280 \sim 320$ $\mathrm{g} / \mathrm{L} \mathrm{Ni}\left(\mathrm{NH}_{2} \mathrm{SO}_{3}\right)_{2} \cdot 4 \mathrm{H}_{2} \mathrm{O}, 20 \sim 100 \mathrm{~g} / \mathrm{L} \mathrm{Na}_{2} \mathrm{WO}_{4} \cdot 2 \mathrm{H}_{2} \mathrm{O}, \quad 35 \sim 45$ $\mathrm{g} / \mathrm{L} \mathrm{H}_{3} \mathrm{BO}_{3}, 40 \sim 100 \mathrm{~g} / \mathrm{L} \mathrm{Na}_{3} \mathrm{C}_{6} \mathrm{H}_{5} \mathrm{O}_{7} \cdot 2 \mathrm{H}_{2} \mathrm{O}, 0 \sim 5 \mathrm{~g} / \mathrm{L}$ ascorbic acid (Vc, as stabilizer), and $0.2 \sim 6 \mathrm{~g} / \mathrm{L}$ saccharin (as stress removal agents and brighteners) were used. A current density of $1 \sim 6 \mathrm{~A} / \mathrm{dm}^{2}$, a pH value of $3 \sim 5$, a temperature of $50 \sim 70^{\circ} \mathrm{C}$, and a copper sheet (as the cathode material) were used for plating. Analytical reagents and deionized water were used to make the plating bath, where $\mathrm{NaOH}$ or $\mathrm{H}_{2} \mathrm{SO}_{4}$ was used to control the $\mathrm{pH}$ value.

A HS-4800 field emission electron microscope (Hitachi, East coast port city, Honshu Island) attached with a INC250 spectrometer (EDS) was used to analyze the content of $\mathrm{Ni}$, $\mathrm{Fe}$, and $\mathrm{W}$ in the NiFeW alloy coatings. A FM-ARS9000 hardness tester was used to measure the hardness of the alloy coatings. The applied force and time were $50 \mathrm{~g}$ and 15 $\mathrm{s}$, respectively. The hardness value was the average of hardness from given measurements. A CHI660A electrochemical workstation was used to measure the polarization curves to derive the corrosion resistance of the alloy coatings in a $3.5 \mathrm{wt} \% \mathrm{NaCl}$ solution. A three-electrode cell, with a NiFeW alloy coating as the working electrode, a platinum piece as the counter electrode, and a saturated calomel electrode (SCE) as the reference electrode (SCE), were used. The polarization curves were measured at an initial potential of $-1.3 \mathrm{~V}$, a final potential of $1.0 \mathrm{~V}$, and a scan rate of $10 \mathrm{mV} / \mathrm{s}$.

\section{Results and Discussion}

\subsection{Influence of $\mathrm{pH}$ on composition, microhardness and deposition rate}

With a bath temperature of $60^{\circ} \mathrm{C}$ and a current density of $4 \mathrm{~A} / \mathrm{dm}^{2}$, the influence of the $\mathrm{pH}$ value of plating bath on the composition, microhardness, and deposition rate of coating was studied. The results are shown in Figs. 1 and 2.

Fig. 1 indicates that the content of both $\mathrm{Fe}$ and $\mathrm{W}$ increases with the $\mathrm{pH}$ value. When the $\mathrm{pH}$ value is increased from 3 to 5 , the content of $\mathrm{W}$ increases from

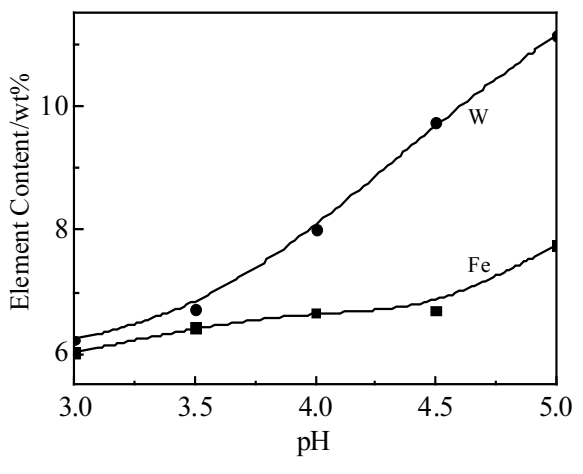

Fig. 1 Composition of the coating vs $\mathrm{pH}$ value of the bath

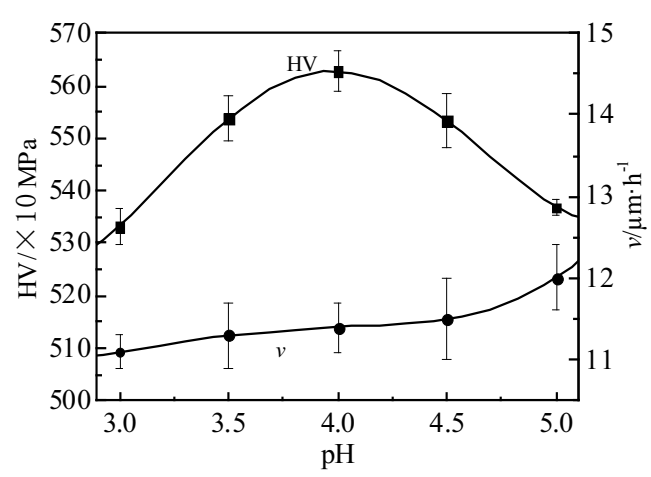

Fig. 2 Microhardness (HV) and deposition rate (v) of the coating vs $\mathrm{pH}$ value of the bath

$6.23 \%$ to $11.15 \%$ (with a net increase of $4.92 \%$ ) whereas the content of Fe increases from $6.02 \%$ to $7.76 \%$ (with a net increase of only $1.74 \%$ ). These results suggest that (i) the influence of the $\mathrm{pH}$ value on the content of $\mathrm{W}$ is stronger than that on the content of $\mathrm{Fe}$ and (ii) it is difficult to control the content of $\mathrm{Fe}$ by only controlling the $\mathrm{pH}$ value. After $\mathrm{Ni}, \mathrm{Fe}, \mathrm{W}$ metal ion and citric acid ion complexation, under different $\mathrm{pH}$ conditions, these complex ions are closely related to the deposition mechanism of $\mathrm{Ni}, \mathrm{Fe}$ and $\mathrm{W}^{[8]}$.

Fig. 2 shows the influence of the $\mathrm{pH}$ value of plating bath on the microhardness (HV) and deposition rate $(v)$ of coating. The hardness increases and decreases with $\mathrm{pH}$ for $\mathrm{pH}=3.0 \sim 4.0$ and 4.0 5.0, respectively. For a relatively small value of $\mathrm{pH}$, hydrogen releases from the cathode region: the lower the $\mathrm{pH}$, the more the content of released hydrogen. The released hydrogen can provide nucleation sites for NiFeW alloy coating, leading to refined grains and higher microhardness, which reaches a maximum of $5628 \mathrm{MPa}$ for $\mathrm{pH}=4.0^{[15]}$. Further increasing the value of $\mathrm{pH}$ from 4.0 to 5.0, however, decreases the content of released hydrogen, makes the plating bath cloudy, and forms iron hydroxides. These iron hydroxides makes the alloy coating rough and brittle, thereby reducing the 
microhardness.

The deposition rate increases slowly with $\mathrm{pH}$ for $\mathrm{pH}<$ 4.5 and increases quickly with $\mathrm{pH}$ for $\mathrm{pH}>4.5$. However, the released hydrogen will result in hydrogen embrittlement, thus affecting the overall performance of the coating. The surface quality of the coating is strongly dependent on the value of $\mathrm{pH}$. For $\mathrm{pH}=3.8 \sim 4.2$, the coating is bright and dense. For $\mathrm{pH}>5.0$, the coating becomes darkened. Further increasing $\mathrm{pH}$ makes the deposition rate too high, thus forming burrs on the surface of the coating and lowering the microhardness of the coating.

\subsection{Influence of temperature on composition, microhardness and deposition rate}

With a $\mathrm{pH}$ value of 4 and a current density of $4 \mathrm{~A} / \mathrm{dm}^{2}$, the influence of the temperature of plating bath on the composition, microhardness, and deposition rate of coating was studied. The results are shown in Figs. 3 and 4.

Fig. 3 indicates that the content of $\mathrm{W}$ first increases and then decreases with the temperature increasing of the plating bath. The content of $\mathrm{W}$ reaches a maximum of $10.8 \%$ at 55 ${ }^{\circ} \mathrm{C}$ and decreases to $6.39 \%$ at $70{ }^{\circ} \mathrm{C}$. In contrast, the content of $\mathrm{Fe}$, which is $10.01 \%$ at $55{ }^{\circ} \mathrm{C}$ and $5.99 \%$ at $70{ }^{\circ} \mathrm{C}$, decreases monotonically with temperature. Clearly, the content of both $\mathrm{W}$ and $\mathrm{Fe}$ largely changes with temperature.

Fig.4 indicates that the deposition rate first increases with temperature and reaches a maximum of $10.4 \mu \mathrm{m} / \mathrm{h}$ at $60^{\circ} \mathrm{C}$. For temperature above $60^{\circ} \mathrm{C}$, the deposition rate decreases slowly with temperature. The decreased deposition rate can be explained by the faster diffusivity and mobility which lowers the concentration polarization of metal ions at higher temperature. The microhardness increases with temperature for temperatures below $60^{\circ} \mathrm{C}$ and decreases with temperature for temperatures above $65^{\circ} \mathrm{C}$, reaching a maximum of 581 between 60 and $65^{\circ} \mathrm{C}$. This is consistent with the change of $\mathrm{W}$ content in the coating.

A higher temperature leads to faster diffusivity and mobility of metal ions. This is helpful to the deposition of metals on cathode. However, compared to the that of $\mathrm{W}$, the deposition rate of $\mathrm{Fe}$ is more limited became the deposition potential of $\mathrm{Fe}$ is higher than that of W. Thus, upon increasing the temperature, the content of $\mathrm{Fe}$ decreases monotonically whereas that of $\mathrm{W}$ has a maximum. A lower temperature results in a lower deposition rate and a darkened surface of the coating. In comparison, a higher temperature results in a higher deposition rate and a smoother surface of the coating. However, a temperature that is too high may decompose the plating solution, thus impeding the deposition of metal ions on cathode and lowering the content of deposited elements on the coating. A too-high temperature may also increase the concentration of $\mathrm{Fe}^{3+}$ in the plating bath, thus forming more iron hydroxides and making the coating brittle. Therefore, the optimal temperature for the plating bath should be between 55 and $65^{\circ} \mathrm{C}$.

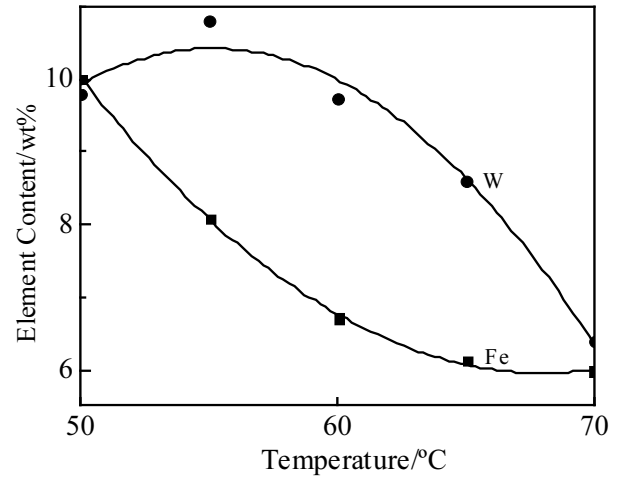

Fig. 3 Composition of the coating vs. temperature of the bath

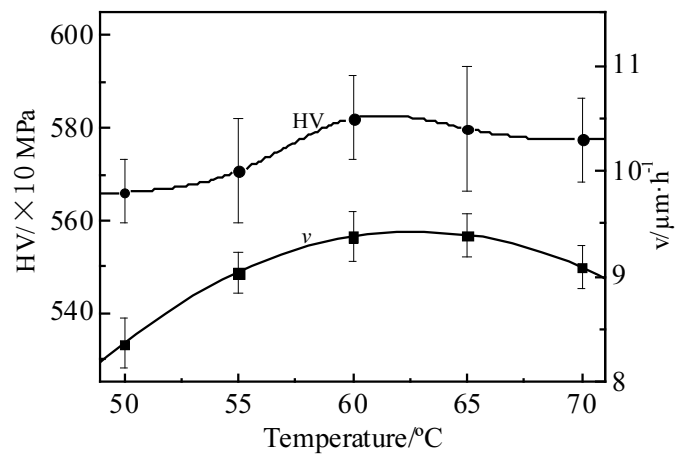

Fig. 4 Deposition rate $(v)$ and Microhardness (HV) of the coatings vs. temperature of the bath

\subsection{Influence of current density on composition, microhardness and deposition rate}

With a temperature of $60^{\circ} \mathrm{C}$ and a $\mathrm{pH}$ of 4.0 , the influence of current density $\left(i_{\mathrm{K}}\right)$ on the composition, microhardness, and deposition rate of coatings was studied. The results are shown in Figs. 5 and 6, from which the optimal current density can be derived.

Fig. 5 suggests that the content of $\mathrm{W}$ increases with $i_{\mathrm{K}}$ (for $i_{\mathrm{K}}<4 \mathrm{~A} / \mathrm{dm}^{2}$ ) and decreases with $i_{\mathrm{K}}$ (for $i_{\mathrm{K}}>4 \mathrm{~A} / \mathrm{dm}^{2}$ ). In contrast, the content of Fe first decreases with $i_{\mathrm{K}}$ and then increases with $i_{\mathrm{K}}$. Clearly, a relatively stable content of deposited elements can be achieved at a current density between 3.8 and $4.2 \mathrm{~A} / \mathrm{dm}^{2}$.

Fig.6 suggests that the microhardness (HV) increases monotonically from $4856 \mathrm{MPa}$ to $5492 \mathrm{MPa}$ when $i_{\mathrm{K}}$ is increased from $1.0 \mathrm{~A} / \mathrm{dm}^{2}$ to $5 \mathrm{~A} / \mathrm{dm}^{2}$. When $i_{\mathrm{K}}$ is small, the polarization of the cathode is weak, leading to a low deposition rate and a large grain size. As a result, the microhardness is low. Increasing the current density makes the polarization of the cathode stronger. This will refine the grain size and increase the dislocation density of the coatings, resulting in stronger coatings ${ }^{[16]}$. 


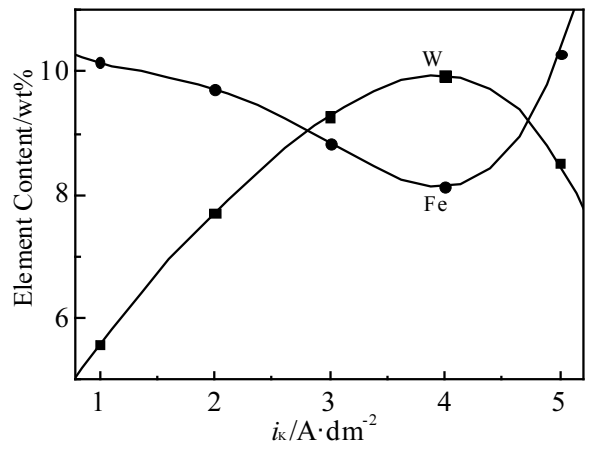

Fig. 5 Composition of the coatings vs. current density

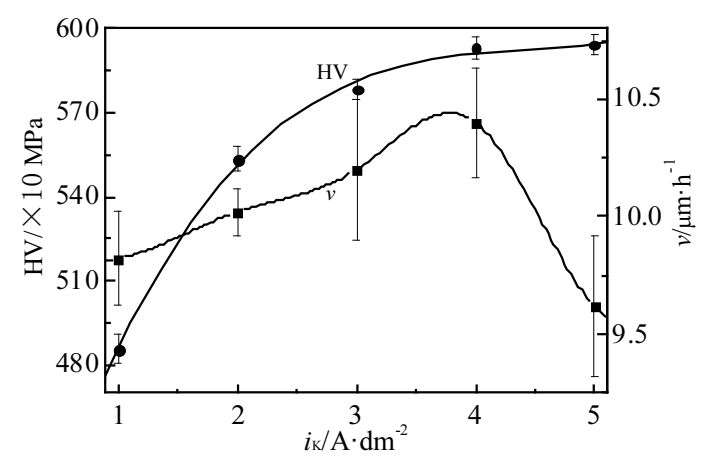

Fig. 6 Microhardness (HV) and deposition rate (v) of the coatings vs. current density

The deposition rate of the coatings first increases and then decreases with $i_{\mathrm{K}}$. When $i_{\mathrm{K}}$ is relatively small, increasing $i_{\mathrm{K}}$ can make the polarization of the cathode stronger, which is beneficial to the deposition of the coatings. However, if $i_{\mathrm{K}}$ is too high, more hydrogen evolves, which lowers the deposition rate and the quality of the coatings. For example, the coating may come with burrs and become coarse or even "scorched". Therefore, the current density should be located between 3.8 and $4.2 \mathrm{~A} / \mathrm{dm}^{2}$.

\subsection{Influence of the concentration of ascorbic acid} on composition, hardness and deposition rate

In the plating bath, $\mathrm{Fe}^{2+}$ is easily oxidized to $\mathrm{Fe}^{3+}$ by oxygen in the air, and $\mathrm{Fe}^{3+}$ is easily hydrolyzed, causing plating bath turbidity and failure. When the amount of $\mathrm{Fe}^{3+}$ is too big in plating bath, its dispersion ability is poor; thus the coating becomes rough and brittle, reducing the binding force of coating with substrate. $\mathrm{Fe}^{3+}$ could be reduced to $\mathrm{Fe}^{2+}$ by ascorbic acid in the plating bath, and the ascorbic acid was oxidized to dehydroascorbic acid simultaneously. Meanwhile, the ascorbic acid could form a complex compound with $\mathrm{Fe}^{2+}$, and the cathodic polarization effect is increased significantly. The dehydroascorbic acid can be reduced to ascorbic acid in electrolytic treatment or plating, and therefore, the ascorbic acid can be used repeatedly ${ }^{[17]}$.

With a $\mathrm{pH}$ of 4.0 , a current density of $4 \mathrm{~A} / \mathrm{dm}^{2}$, and a temperature of $60^{\circ} \mathrm{C}$, the influence of the concentration of ascorbic acid on the composition, hardness, and deposition rate of coatings was studied. The results are shown in Figs. 7 and 8.

Fig.7 suggests that the content of $\mathrm{W}$ in the coatings increases with the concentration of ascorbic acid, $V \mathrm{c}$, and reaches $\sim 11.5 \mathrm{wt} \%$ at the highest $V \mathrm{c}$. When $V \mathrm{c}$ is increased from 0 to $2 \mathrm{~g} / \mathrm{L}$, the content of $\mathrm{Fe}$ increases with $V \mathrm{c}$. For $V \mathrm{c}>$ $2 \mathrm{~g} / \mathrm{L}$, the content of $\mathrm{Fe}$ is almost constant. Fig. 7 also indicates that the deposition behavior of $\mathrm{Fe}$ and that of $\mathrm{W}$ is similar, suggesting that Fe and $\mathrm{W}$ can be easily co-deposited. Although there have been many reports on the triggered co-deposition of $\mathrm{Fe}$ and $\mathrm{W}$, the detailed mechanism remains unclear $^{[11]}$.

Fig. 8 indicates that, upon increasing $V \mathrm{c}$, the deposition rate $(v)$ of the coatings decreases monotonically from 10.6 to $9.90 \mu \mathrm{m} / \mathrm{h}$. This can be explained by that $\mathrm{Fe}^{2+}$ ions complex with the ascorbic acid to form complex ions. The activation energy of discharging the complex ions is higher than that of hydrated ions ${ }^{[17-22]}$. Thus, the cathodic polarization of the complex ions increases whereas the deposition potential becomes negative. These lead to evolved hydrogen and less electrical energy for deposition, making the deposition rate lower.

In comparison, upon increasing $V \mathrm{c}$, the microhardness decreases. However, there exist fluctuations in the microhardness of the coatings. This may be explained by that more hydrogen evolves upon increasing $V \mathrm{c}$, making the surface of the coatings looser and lowering the microhardness. Therefore, $V \mathrm{c}$ should be kept at a lever as low as possible. The appropriate $V \mathrm{c}$ for the present plating is $3 \mathrm{~g} / \mathrm{L}$.

\subsection{Corrosion resistance of $\mathrm{NiFeW}$ alloy coatings}

Fig.9 shows the polarization curves of NiFeW alloy coatings deposited by four different sets of parameters, with one set of parameters being the optimal deposition parameters (ODPs). The corrosion potential for the ODPs is $-0.60 \mathrm{~V}$, which is more positive than those for other three sets of parameters. With the ODPs and a voltage above 0.15

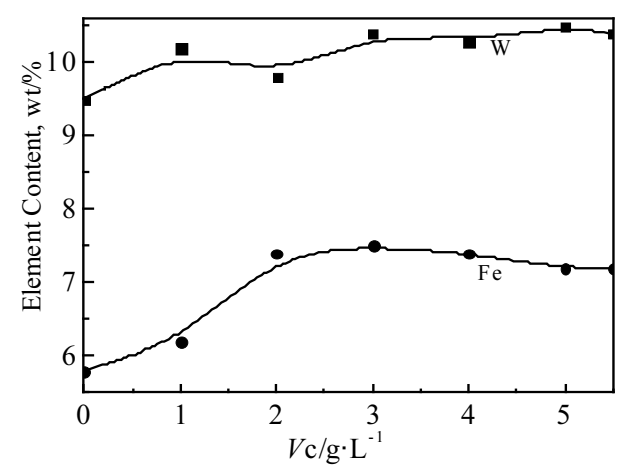

Fig. 7 Composition of the coatings vs. the concentration $(V \mathrm{c})$ of ascorbic acid 


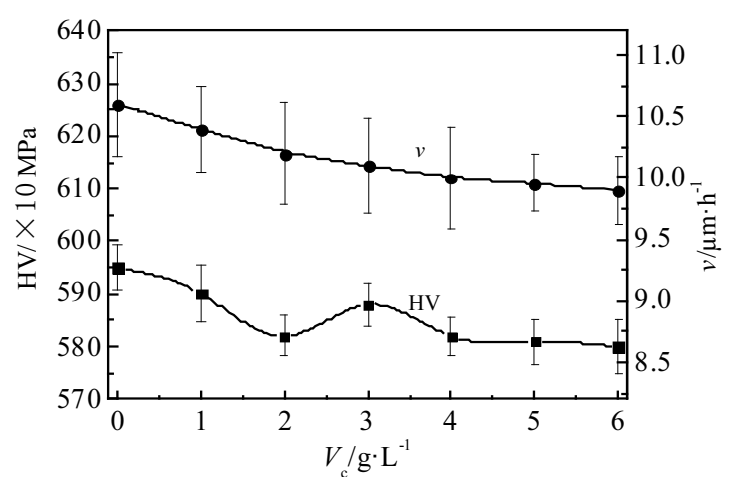

Fig. 8 Microhardness (HV) and deposition rate (v) of the coatings vs. the concentration $(V \mathrm{c})$ of ascorbic acid

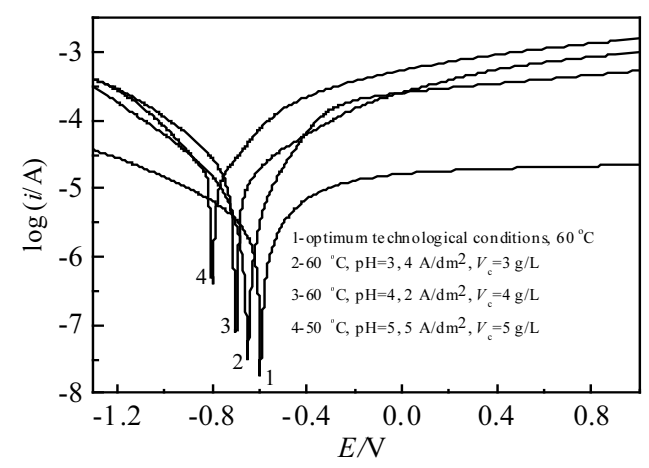

Fig. 9 Polarization curves of $\mathrm{NiFeW}$ alloy coatings deposited under different sets of parameters

$\mathrm{V}$, the current is almost constant with increasing voltage. This suggests that the surface of coating is passivated, i.e., a passivated layer is formed on the surface of coating. This passivated layer can prevent further corrosion of the coating. The passivation also occurs at $\sim-0.3 \mathrm{~V}$ by the following set of parameters: $60^{\circ} \mathrm{C}, \mathrm{pH}=3,4 \mathrm{~A} / \mathrm{dm}^{2}, V \mathrm{c}=3 \mathrm{~g} / \mathrm{L}$. Clearly, the coating deposited with the optimal parameters has the highest corrosion resistance, which mainly results from the smooth and dense surface, the smallest grain size, the least cracks and impurities, and the fact that the $\mathrm{Cl}^{-}$ions in the plating solution is difficult to penetrate coatings.

\section{Conclusions}

1) The deposition rate increases and the content of both $\mathrm{Fe}$ and $\mathrm{W}$ increases with the $\mathrm{pH}$ value. The microhardness increases and decreases with $\mathrm{pH}$ for $\mathrm{pH}=3.0 \sim 4.0$ and 4.0 5.0, respectively, which reaches a maximum of 562.83 at $\mathrm{pH}=4.0$.

2) The content of $\mathrm{Fe}$ decreases monotonically with temperature. The content of $\mathrm{W}$, deposition rate and microhardness first increases and then decreases with the temperature of the plating bath.

3) The content of $W$ and the deposition rate of the coatings first increases and then decreases with $i_{\mathrm{K}}$. In contrast, the content of Fe first decreases and then increases with $i_{\mathrm{K}}$. The microhardness (HV) increases monotonically with $i_{\mathrm{K}}$.

4) The content of $\mathrm{W}$ in the coatings increases with the concentration of ascorbic acid. When $V$ c is increased from 0 to $2 \mathrm{~g} / \mathrm{L}$, the content of Fe increases with $V \mathrm{c}$. For $V \mathrm{c}>2 \mathrm{~g} / \mathrm{L}$, the content of $\mathrm{Fe}$ is almost constant. With increasing $V \mathrm{c}$, the deposition rate and microhardness of the coatings decrease monotonically.

5) The optimal deposition parameters for $\mathrm{NiFeW}$ alloy coatings is: $\mathrm{pH}=4$, temperature $=60^{\circ} \mathrm{C}$, current density $=4 \mathrm{~A} / \mathrm{dm}^{2}$, and $V \mathrm{c}=3 \mathrm{~g} / \mathrm{L}$. The coating deposited by these optimal parameters has the highest corrosion resistance.

\section{References}

1 Crowson A, Chen E S. Journal of the Minerals, Metals and Materials Society[J], 1991, 43: 27

2 He F J, Wang M, Lu X. Transactions of Nonferrous Metals Society of China [J], 2006, 16: 1289

3 Ribić-Zelenović L, Ćirović N, Spasojević M et al. Materials Chemistry and Physics[J], 2012(2): 212

4 Donten M, Cesiulis H, Stojek Z. Electrochimica Acta[J], 2000, 45: 3389

5 Zhan H Q, He F J, Ju H et al. Materials Protection[J], 2008, 41: 31 (in Chinese)

6 Aldrighi Luiz M O, Josiane D C, Mikarla B. D S et al. Journal of Alloys and Compounds[J], 2015, 619: 697

7 Moussa S O, Ibrahim M A M, Aboelrehim S S. Journal of Applied Electrochemistry[J], 2006, 36: 333

8 Atanassov N, Cencheva K, Bratoeva M. Plating and Surface Finishing[J], 1997, 84: 67

9 Kim D K, Lee S, Song H. Metallurgical and Materials Transactions $A[\mathrm{~J}], 1998,29: 1057$

10 Wang Y, Yuan X T, Yu H Y et al. Materials Protection[J], 2011, 44: 44 (in Chinese)

11 Gáliková Z, Chovancová M, Danielik V. Chemical Papers[J], 2006, 60: 353

12 Zemanová M, Kurinec R, Jorík V et al. Chemical Papers[J], 2012, 66: 492

13 Zhong Z M, Clouser S J. Surface and Coatings Technology[J], 2014, 240: 380

14 Zhang Peng. Study on the Process and Properties of Ni Few Alloy Coatings Produced by Pulse Electrodeposition[D]. Wuxi: Jiangnan University, 2007 (in Chinese)

15 Sriraman K R, Raman S G S, Seshadri S K. Materials Science and Engineering $A[\mathrm{~J}], 2007,460-461: 39$

16 Yao Y W, Yao S W, Zhang L et al. Materials Letters[J], 2007, $61: 67$

17 Geng Q J, Feng L M, Xia X H. Electroplating and Finishing [J], 2007, 26: 14 (in Chinese)

18 Islam S H. Rare Metals[J], 2011, 30: 392

19 Sriraman K R, Raman S G S, Seshadri S K. Materials Science and Technology[J], 2006, 22: 14

20 He F J, Yang J, Lei T X et al. Applied Surface Science[J], 
2007, 253: 7591

21 Wu Y C, Shu X, Xie T et al. China Surface Engineering[J], 2005,18: 1 (in Chinese)
22 Zhan $\mathrm{H}$ Q, He F J, Ju H et al. Electroplating and Finishing $[\mathrm{J}]$, 2009, 28: 1 (in Chinese)

\section{工艺参数及稳定剂抗坏血酸对电沉积 $\mathrm{NiFeW}$ 合金镀层的影响}

于金库 ${ }^{1}$, 赵莉莉 ${ }^{1}$, 孙 ${ }^{\text {会 }}{ }^{1}$, 王跃华 ${ }^{1}$, 于美琪 ${ }^{2}$, 骆洪亮 ${ }^{2}$, 许哲峰 ${ }^{2}$, 松木一弘 ${ }^{2}$

(1. 燕山大学 亚稳材料制备技术与科学国家重点实验室, 河北 秦皇岛 066004)

(2. 広島大学工学研究院, 広岛県東広島市 镜山 1-4-1 739-8527)

摘 要: 为获得性能良好的镍铁铇合金镀层, 研究了镀液 $\mathrm{pH}$ 值、温度、电流密度、稳定剂抗坏血酸浓度对镍铁铇合金镀层成分和镀 层沉积速率、显微硬度的影响。结果表明: 镀液 $\mathrm{pH}$ 值对镀层 $\mathrm{W}$ 含量和镀层沉积速率影响较大; 镀液温度对镀层沉积速率、镀层成分和 镀层硬度影响均较大; 随抗坏血酸浓度增加, 镀层沉积速率逐渐降低, 镀层表面形貌更加粗粘。在镀液 $\mathrm{pH}=4$, 温度 $60{ }^{\circ} \mathrm{C}$, 电流密度 4 $\mathrm{A} / \mathrm{dm}^{2}$, 抗坏血酸浓度 $3 \mathrm{~g} / \mathrm{L}$ 时, 镀层沉积速率和镀层的显微硬度较高, 表面光亮致密, 耐蚀性好。

关键词: 镍铁铇合金镀层; 电沉积; 显微硬度; 耐蚀性

作者简介: 于金库, 男, 1962 年生, 博士, 教授, 燕山大学材料科学与工程学院, 河北 秦皇岛 066004, 电话: 0335-8074792, E-mail: yujinku@ysu.edu.cn 